\title{
Aboveground Biomass of Selected Provenances of Acacia Mangium and Acacia Aulacocarpa Multiple-leadered Trees
}

\author{
Sapari Mat \\ Department of Forest Production
}

Faculty of Forestry, Universiti Putra Malaysia

43400 Serdang, Selangor, Malaysia

Tel: 60-3-8946-7201Ｅ-mail: saparimat@yahoo.com

Nor-Aini Ab-Shukor (Corresponding author)

Laboratory of Sustanaible Bioresource Management

Institute of Tropical Forestry \& Forest Products /

Department of Forest Production

Faculty of Forestry, Universiti Putra Malaysia

43400 Serdang, Selangor, Malaysia

Tel: 60-3-89467186Ｅ-mail: anishukor@yahoo.com

Mohd-Zaki Hamzah

Department of Forest Production

Faculty of Forestry, Universiti Putra Malaysia

43400 Serdang, Selangor, Malaysia

Tel: 60-3-8946-7170Ｅ-mail: zakihamzah@yahoo.com

Rosenani Abu-Bakar

Department of Land Management

Faculty of Agriculture, Universiti Putra Malaysia

43400 Serdang, Selangor, Malaysia

Tel: 60-3-894-6981Ｅ-mail: rosenani@agri.upm.edu.my

Mohd-Fauzi Ramlan

Department of Crop Science

Faculty of Agriculture, Universiti Putra Malaysia

43400 Serdang, Selangor, Malaysia

Tel: 60-3-8946-7269Ｅ-mail: fauzi@agri.upm.edu.my

Hazandy Abdul-Hamid

Department of Forest Production

Faculty of Forestry, Universiti Putra Malaysia

43400 Serdang, Selangor, Malaysia

Tel: 60-38946-7585 E-mail: hazandy@gmail.com

Abdul-Latib Senin

Faculty of Forestry, Universiti Putra Malaysia

43400 Serdang, Selangor, Malaysia

Tel: 60-3-8946-7219 E-mail: alsenin60@hotmail.com 
The research was financed by the Ministry of Science, Technology and Innovation. IRPA: EA 0009913

\begin{abstract}
Acacia mangium Willd. and Acacia aulacocarpa A. Cunn Ex. Benth are two important Acacias for biomass production. Being multiple-leader (ML) and fast growing species, both species are the best bet for carbon sequestration and bio-energy supplementary. The main objective of this study was to assess the aboveground biomass and to derive aboveground biomass equations of these species and provenances. Destructive sampling was carried out with 36 samples per species and diameter at breast height (Dbh) and categorized into three classes namely small $(11-15 \mathrm{~cm})$, medium $(16-20 \mathrm{~cm})$ and big $(21-25 \mathrm{~cm})$ for $A$. mangium and $6-10 \mathrm{~cm}, 11-15 \mathrm{~cm}$ and $16-20 \mathrm{~cm}$ for $A$. aulacocarpa respectively. A. mangium from SW of Boset WP (PNG) produced $380.83 \mathrm{t} / \mathrm{ha}$ of aboveground biomass, Captain Billy Road (QLD), Bansbach WP (PNG) (224.44 t/ha) and Russel and Gap CK (QLD) (49.63 t/ha) while for A. aulacocarpa; provenance from Arufi E Morehead WP (PNG) (171.88 t/ha), W. Morehead (PNG) (150.90 t/ha), Samford (QLD) (63.87 t/ha) and 3K S Mt. Larcom (QLD) (25.32 t/ha) respectively.
\end{abstract}

Keywords: Acacia mangium, Acacia aulacocarpa, Multiple-leader, Aboveground Biomass, Provenance

\title{
1. Introduction
}

Estimating tree and forest biomass is essential for assessing ecosystem yield and carbon stock in compliance with the Kyoto Protocol on greenhouse gas reduction (Korner, 2005). Biomass is being frequently used to quantify traditional forest products (Guttenberg, 1973; Husch et al., 1982) and as estimated value of wood as a raw material. Therefore determining biomass is a useful way of providing estimates of the quantity of these components. Biomass studies for different forest types in the world have been intensified under the International Biological Programme (IBP) in the 1970s (Brown, 1997).

Currently, the forest biomass studies have increased in the past several years as basic ecosystem data that are needed for the development of sound ecological land management and to predict the dynamics and productivity of the forests (Melillo et al., 1993). Prior to 1980, biomass information in the world was rather limited in the tropical countries. In recent years, biomass studies in the tropics have been conducted by many researchers such as Kato et al. (1978), Kawahara et al. (1981), Brown et al. (1991), and Brown (1997). They found that the biomass production varied among species and sites. The species-site interactions were the main concern to use the established biomass equations.

Ledin and Willebrand (1996) noted that maximum biomass production can be achieved by optimizing genotype and/or cultural management and it can be viewed over a spectrum of spatial or temporal scales (Harris et al., 1973). At the largest scale, entire region are being examined to determine (i) the rate of succession, (ii) productivity profiles, (iii) the potential impacts of various harvest strategies on production and biomass (Sharpe and Johnson, 1973), (iv) carbon cycle (Brown, 1997) and energy supply (Jackson and Jackson, 1997). While at the smallest scale, the physiological processes such as photosynthesis, respiration and decomposition which are integral to biomass have been studied. These could help to establish their in situ relationship to environmental variables, biomass accumulation and turnover (Harris et al., 1973).

In this study, we examined the accumulation of aboveground biomass and also developed equations based on growth data in four provenances of Acacia mangium and A. aulococarpa from two regions in a progeny trial. Acacia species have shown tremendous growth performance in many research sites and provenance trials (Thinh et al., 1998; Bino, 1998). These species grow well on both lowland and highland especially in Vietnam and Papua New Guinea. $A$. mangium produces height of $25 \mathrm{~m}$ to $35 \mathrm{~m}$ with straight bole and the diameter at breast height (Dbh) can be over $60 \mathrm{~cm}$. However, on relatively poor sites the trees are usually much smaller, with average heights between $7 \mathrm{~m}$ to $10 \mathrm{~m}$ (Turnbull, 1986). On the other hand, provenance trials of $A$. aulacocarpa conducted at Cebu Province, Philippines revealed that the species could reach $6.5 \mathrm{~m}$ after two years of planting (Baggayan and Baggayan, 1998), but exhibited poor survival of only $38 \%$. After 5 years in the field trial at Da Chong, Dong Ha and La Nga at Vietnam, A. mangium outperformed $A$. aulacocarpa where the former species recorded $10 \mathrm{~cm}$ in means of respectively Dbh and $8.1 \mathrm{~m}$ in height while the latter species recorded $7.2 \mathrm{~cm}$ and $6.0 \mathrm{~m}$ respectively (Nghia and Kha, 1998).

\section{Materials and Methods}

\subsection{Site Selection}

The study area utilized a progeny trial which was established on August 1998 in How Swee Estate, Kampung Aur Gading, Kuala Lipis, Pahang Darul Makmur which is located about $130 \mathrm{~km}$ from Kuala Lumpur. The latitude and longitude of the trial are $4^{\circ}$ and $20.5^{\prime} \mathrm{N}$ and $101^{\circ}$ and 55.5' E. Previously, the estate was planted with rubber trees (Hevea brasiliensis). The estate area is situated approximately $91 \mathrm{~m}$ above sea level. In general it has a uniform topography and considered as a flat area. It receives mean annual temperature, relative humidity and rainfall of $30^{\circ} \mathrm{C}$, $70 \%$ and $2515.28 \mathrm{~mm}$ respectively. 


\subsection{Plant Materials}

This study utilized plant materials of a seventh year old progeny trial involving two important Acacia species namely Acacia mangium and Acacia aulacocarpa. This study only focused on two out of four species planted due to their high occurrence of ML formation. For each species, there are four provenances, thus a total of eight provenances for this study. To overcome the confounding effect, every samples were classified into Dbh classification. This is due to the establishment of the research area which was based on provenance/ genotype trial which every species/ provenance/ genotype were assigned randomly within lines and blocks. The samples located at the verge of the block were removed from the selected samples. The original sources of these seeds were supplied by the Commonwealth Scientific and Industrial Research Organization (CSIRO).

\subsection{Assessment of the aboveground biomass (AGB) of Acacia mangium and Acacia aulacocarpa multiple-leadered trees}

Aboveground biomass evaluation was based on mean biomass per provenances, AGB equations for each provenance and the AGB estimation based on one hectare with the tree spacing of $3 \mathrm{~m} \times 3 \mathrm{~m}$ apart. Details of assessment of this parameter are given as follows:

Prior to determination of performance, total enumeration on their Dbh and height was carried out to assess the overall variation and distribution of ML trees within the species and provenances. The data were sorted accordingly from the lowest to the highest range Dbh and height. Then, they were divided into three classes according to Dbh groupings to hinder the confounding effects. For each group, the mean value of Dbh and height were calculated. Three samples with the nearest values to the average value of each class were chosen as samples to represent each group. Then, this was followed with ground checking to verify and identify these samples. The selected trees were then marked with ribbon for the purpose of identification in the field.

The diameter at breast height was classified into three classes namely small, medium and big. They are: Small (11-15 $\mathrm{cm})$, Medium $(16-20 \mathrm{~cm})$ and Big $(21-25 \mathrm{~cm})$ for A. mangium and 6-10 cm, 11-15 cm and 16-20 cm for A. aulacocarpa respectively. In each class; there were three replications, thus making a total of $9 \mathrm{ML}$ trees per provenance utilized in this experiment. There were $72 \mathrm{ML}$ trees involved in this destructive sampling. ML class 2 was utilized in this experiment as it was only under this category which contained sufficient numbers of trees to be assessed for this study.

Before the trees were felled, the area above ground level was cleared and cleaned to avoid any sample contamination. A chain saw was used to fell the trees and cut the components to a smaller size. Then, samples of biomass were divided into three components namely stem, branch/ twigs and foliage. All the components were weighed to obtain the total fresh weight. The main stem was further divided into three parts namely bottom, middle and top. A $10 \mathrm{~cm}$ disc wood from each part was weighed for dry weight. $100 \mathrm{~g}$ of foliage were taken in three replicates using Digi Digital Weighing Scale $(1.5 \mathrm{~kg} \pm 0.05 \mathrm{~g})$. Samples of wood disc and the foliage were oven-dried at $108^{\circ} \mathrm{C}$ for 48 hours (memmert, $200^{\circ} \mathrm{C}$ $\pm 0^{\circ} \mathrm{C}$ ) until constant weight was achieved (Kato et al. 1978). The samples were then subjected to the follow equation to determine their biomass production:

$$
\text { Biomass }=[\mathrm{DW} / \mathrm{FW} * 100 \%] * \mathrm{TFWC}
$$

Where:

$\begin{array}{ll}\text { FW } & : \text { Fresh Weight }(\mathrm{kg}) \\ \text { DW } & : \text { Dried Weight }(\mathrm{kg}) \\ \text { TFWC } & \quad: \text { Total Fresh Weight Components }(\mathrm{kg})\end{array}$

Then the components of biomass were summed up to obtain the estimation of aboveground biomass (AGB). Diameter at breast height and height were incorporated to derive AGB equations using Multiple Linear Regression (SPSS ver. 12). The multiple linear regressions were used to predict for the variance in the interval dependent, based on linear combinations of interval, dichotomous or dummy independent variables. Biomass estimates employed in this study followed a Dbh-based regression established by Kato et al. (1978). Most biomass studies using allometric relations have utilized Dbh as the independent variable because of its ease of measurement and direct relation to tree growth (Jumanne et al., 1983).

\section{Results and discussions}

The results for both species were analyzed separately because they were considered as different entities in relation to different responses to treatment.

\subsection{Aboveground biomass for Acacia mangium}

From the analysis of variance (ANOVA) of aboveground biomass (AGB) components of $A$. mangium ML provenances indicated significantly differences at $\mathrm{P} \leq 0.05$ between provenances for stem and total biomass and on the other hand, for Dbh classes; all the parameters measured were significantly different (Table 1). However, the interaction between 
provenance and Dbh classes were insignificant for provenance differences. This could infer that provenances and Dbh classes were not inter-related or dependent on each other. In addition, Figure 1 shows the summary of mean values of AGB component of $A$. mangium ML provenances and Dbh classes based on per standing trees. Provenance from SW of Boset WP, PNG produced higher mean of AGB (400.19 kg) followed by Bensach WP, PNG (234.15 kg), Captain Billy Road, QLD (211.95 kg) and Russel \& Gap CK, QLD (202.68 kg). The DMRT also shows that the amount of total AGB and stem biomass for SW of Boset WP (PNG) was significantly different from other provenances. However there was no significant difference between provenances with regards to other variables such as branch/ twigs and foliage biomass. The Dbh classification also shows that the total biomass and stem biomass were accordingly to Dbh classification namely big, medium and small Dbh classes. On the other hand, there was no significant different for Dbh classes of big and medium with regard to branch/ twigs and foliage biomass.

\subsection{Aboveground biomass for Acacia aulacocarpa}

Similarly for $A$. aulacocarpa $\mathrm{ML}$ provenances also showed significant differences at $\mathrm{P} \leq 0.05$ between provenances, Dbh classes and interaction between them (Table 1). However, the branch and twigs were not significant with regards to their interactions factors. Figure 2 shows the summary of mean values of AGB components of $A$. aulacocarpa ML provenances and Dbh classes. Provenance from Arufi E. Morehaed WP gave the highest total of aboveground biomass (219.72 kg) followed by W. Morehead, PNG (209.03 kg), Samford, QLD (91.25 kg) and 3K S Mt Larcom, QLD (34.12 $\mathrm{kg}$ ). Provenances from Papua New Guinea shows were significant different from the ones from Queensland in terms of stem, foliage and total AGB. The Dbh classes showed that the Dbh "big" class was significantly different from the other two classes of Dbh for stem biomass, foliage biomass and total AGB. In addition, there is no significant different for classes of Dbh "medium" and "small" with regards to branch and twigs biomass.

\subsection{Correlations and biomass equations}

A Pearson's Correlation Coefficient was conducted with regards to AGB and growth parameters. It was found that Dbh and tree height was highly correlated with AGB for both species $\left(\mathrm{R}^{2}>0.96\right)$. In addition, eight regression equations were also projected to estimate AGB per one hectare basis and they were shown in Table 2. Again, A. mangium from SW of Boset WP (PNG) was found to outperformed the other provenances and recorded the highest estimated AGB per hectare of 380.83 tons/ ha followed by Captain Billy Road (QLD) 251.17 tons/ ha, Bensbach WP (PNG) 244.44 tons/ ha, and Russel and Gap CK (QLD) 49.63 tons/ ha. SW of Boset WP (PNG) provenance was more than 700\% better compared to Russel and Gap CK (QLD) provenance in terms of total AGB. The occurrence could be due to the influence of the stress trees where slow performed trees such as the ones from Russel and Gap CK were actually suppressed by the good performing trees from other provenances. Meanwhile for A. aulacocarpa, provenance from Arufi E. Morehead WP (PNG) produce the estimated of biomass of 171.88 tons/ ha and followed by W. Morehead (PNG) 150.90 tons/ ha, Samford (QLD) 63.87 tons/ ha and 3K S Mt Larcom (QLD) 25.32 tons/ ha respectively.

In addition, the regression analysis for both species revealed that there are strong correlations between total aboveground biomass and Dbh in all provenances ranging from 0.81 to 0.98 for $A$. mangium and from 0.74 to 0.99 for $A$. aulacocarpa. The multi-linear regression was also constructed using the interactions of Dbh and tree height but the correlations results were found to be relatively low if only Dbh was used. The statement was supported by the correlation results where it is proven that Dbh was strongly correlated with AGB compared to height (Table 2). The AGB equations clearly showed that seven out of eight provenances of this study showed that Dbh was the main factor supporting the equations which was actually similar to Zianis and Mencuccini (2002) on Fagus sylvatica. Interestingly, there was higher amount of AGB being showed lower by $\mathrm{R}^{2}$ compared with the lower amount of AGB in A. mangium. Both species showed strong equations correlation based on Guilford's Rule of Thumb (Guilford, 1956). Even though the results of the estimated AGB could be used as early indicator for the species/provenances performance but site-dependent variation in biomass accumulation have been reported by Kondo and Oshima (1981) for Helianthus tuberosus species and three Betulaceae species by Walters et al. (1993). They concluded that, there were significantly different in terms of biomass productions with regards to species and sites.

\section{Conclusion}

Based on the results, aboveground biomass of Acacia mangium and Acacia aulacocarpa were subjected to diameter at breast height (Dbh) rather than tree height. Even though the aboveground biomass production of $A$. mangium relatively higher than A. aulacocarpa, further study should be undertaken to assess the calorific value of these species. This is because, the absolute performance in terms of energy is not the amount of wood in kilograms or tonnes per hectares but depends on the calorific value per gram of wood burned.

\section{Acknowledgement}

We have to remember Mr. Salim, Mr. Zakaria and Mohd Noor Hisham for their help during the field experiment and graphic design. This project wouldn't be reality without supports from CSIRO for providing plant materials. The project was funded by MOSTI under the competitive grant IRPA/EA 0009913. 


\section{References}

Baggayan, J.L. \& Jr. R.L. Baggayan. (1998). Potential of selected Acacia species in Cebu Province, Philippines. In Recent developments in Acacias planting in Proceedings of an international workshop, eds. Turnbull, J.W., H.R. Crampton \& K. Pinyopusarerk, p. 125-129. ACIAR. Hanoi: Vietnam.

Bino, B. (1998). The performance of Acacia angustissima, A. auriculiformis and A. mangium as potential agroforestry tree species in the highlands of Papua New Guinea. In Recent developments in Acacias planting in Proceedings of an international workshop, eds. Turnbull, J.W., H.R. Crampton and K. Pinyopusarerk, p. 45-50. ACIAR. Hanoi: Vietnam.

Brown, S. (1997). Estimating biomass and biomass change of tropical forests. FAO Forestry Paper, 134, 1-40.

Brown, S., A.J.R. Gillespie and A.E. Lugo. (1991). Biomass of tropical forest of South and Southeast Asia. Canadian Journal of Forest Research, 21, 111-117.

Guttenberg, S. (1973). Evolution of weight scaling. 227:12. United States: Southern Lumberman.

Harris, W.F., R.A. Goldstein and G.S. Henderson. (1973). Analysis of forest biomass pools, annual primary production and turnover of biomass for a mixed deciduous forest watershed. IUFRO Biomass Studies. pp 41-64.

Husch, R.C., C.I. Miller and B.T. Beer. (1982). Forest mensuration. Third ed., John Wiley and Sons, p. 63-79. New York. Jackson, A.R.W. and J.M. Jackson. (1997). The natural environment and human impact. In Environmental science, p. 185-195. Singapore: Longman Singapore Publisher Ltd.

Jumanne, A. M., M. K. Esther and D.H. Rene. (1983). Biomass and nutrient accumulation in young Prosopis juliflora at Mombasa, Kenya. Agroforestry Systems 1: 313-321.

Kato, R., H. Ogawa and Y. Tadaki. (1978). Plant biomass and growth increment studies in Pasoh Forest. Malayan Nature Journal, 30, 211-224.

Kawahara, T., Y. Kanazawa and S. Sakurai. (1981). Biomass and net production of man made forest in Philippine. Journal of Japan Forestry Society, 63(9), 320-327.

Kondo, Y. and Y. Oshim. (1981). Propagule size and growth of plant phenomenon of gaining in growth by plants handicapped by small initial size. Japanese Journal of Ecology, 31 (2), 217-219.

Korner, C. (2005). Slow in, rapid out-carbon flux studies and Kyoto targets. Science, 300, 1242-1243.

Ledin, S. and E. Willebrand. (1996). Handbook on how to grow short rotation forests. Department of Short Rotation Forestry. Swedish University of Agriculture.

Lim, M.T. (1993). Growth and yield. In Acacia mangium Growing and utilization, eds. Kamis Awang and D. Taylor, p. 149-161. Winrock International and FAO, Bangkok, Thailand.

Lim, T.M. (1988). Studies an Acacia mangium in Kemasul Forest, Malaysia. I. Biomass and productivity. Journal of Tropical Ecology, 4, 48-56.

Melillo, J.M., A.D. McGuire, D.W. Kicklighter, B. Moore, C.J. Vorosmarthy, and A.L. Schloss. (1993). Global climate change and terrestrial net primary production. Nature 363, 234-240.

Nghia, N.H. and L.D. Kha. (1998). Selection of Acacia species and provenances for planting and Vietnam. In Recent developments in Acacias planting in Proceedings of an international workshop, eds. Turnbull, J.W., H.R. Crampton and K. Pinyopusarerk, p. 45-50. ACIAR. Hanoi: Vietnam.

Sharpe, D.M. and W.C. Johnson. (1973). The biomass dynamics of commercial forest of the Tennesse Valley. IUFRO Biomass Studies. p. 143-157.

Thinh, H.H., L.D. Kha, S.D. Searle and H.V. Tung. (1998). Performance of Australian temperate Acacias on subtropical highlands of Vietnam. In Recent developments in Acacias planting in Proceedings of an international workshop, eds. Turnbull, J.W., H.R. Crampton and K. Pinyopusarerk, p. 45-50. ACIAR. Hanoi: Vietnam.

Turnbull, J.W. (1986). Multipurpose Australian trees and shrubs: Lesser-known species for fuelwood and agroforestry. ACIAR Monograph No. 1. Canberra, Australia: Australia Centre for International Agriculture Research.

Zianis, D. and M. Mencuccini. (2002). Aboveground biomass relationship for Beech (Fagus meosiaca Z. trees in Vermio mountain, Northern Greece. Forest Science, 60, 439-448. 


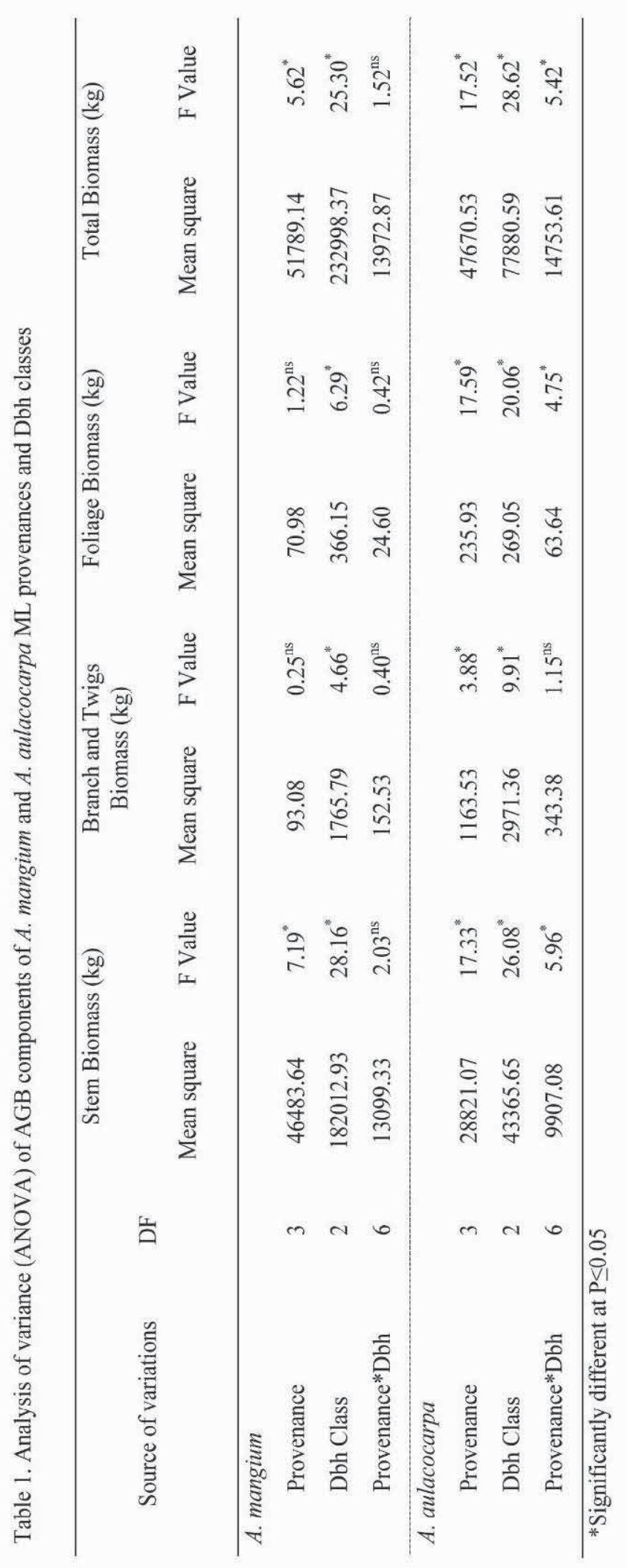


Table 2 . The summary of aboveground biomass equations

\begin{tabular}{|c|c|c|c|c|}
\hline Species & Provenance & Equation & $\mathrm{R}^{2}$ & $\begin{array}{c}\text { Estimated } \\
\text { Biomass/ ha }\end{array}$ \\
\hline \multirow[t]{4}{*}{ A. mangium } & Bansbach WP (PNG) & $y=15.1 x-161.71$ & 0.8085 & 224.44 \\
\hline & SW of Boset WP (PNG) & $y=24.538 x-314.52$ & 0.909 & 380.83 \\
\hline & Captain Bily Road (QLD) & $y=14.743 x-130.5$ & 0.9256 & 251.17 \\
\hline & Russel and Gap CK (QLD) & $y=21.966 x-254.02$ & 0.976 & 49.63 \\
\hline \multirow[t]{4}{*}{ A. aulacocarpa } & W. Morehead (PNG) & $y=18.504 x-182.32$ & 0.9923 & 150.90 \\
\hline & Arufi E Morehead WP (PNG) & $y=21.175 x-213.59$ & 0.9864 & 171.88 \\
\hline & 3K S Mt Larcom (QLD) & $y=6.5299 x-29.432$ & 0.955 & 25.32 \\
\hline & Samford (QLD) & $y=11.436 x-55.678$ & 0.7427 & 63.87 \\
\hline
\end{tabular}




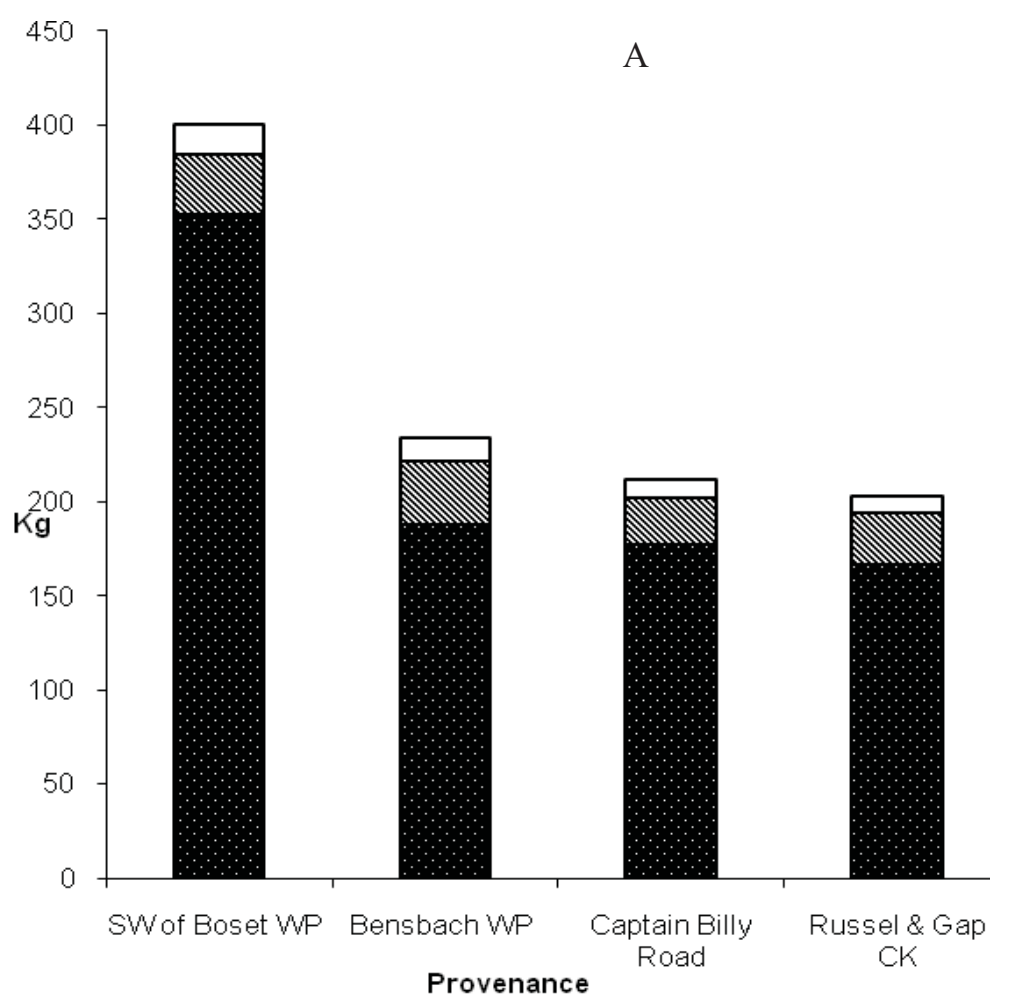

- Stem $\mathbf{8 B r a n c h} \&$ Twigs $\quad$ Foliage

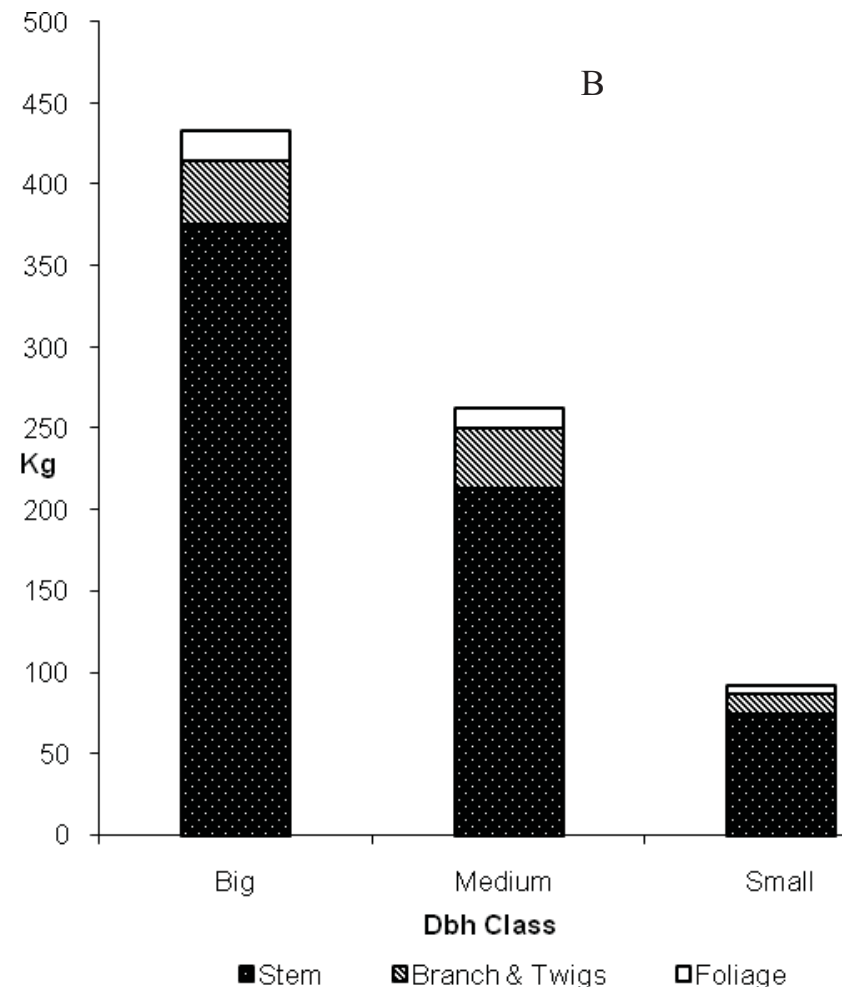

Figure 1. Total aboveground biomass of Acacia mangium with regards to provenances (A) and Dbh classes (B) 


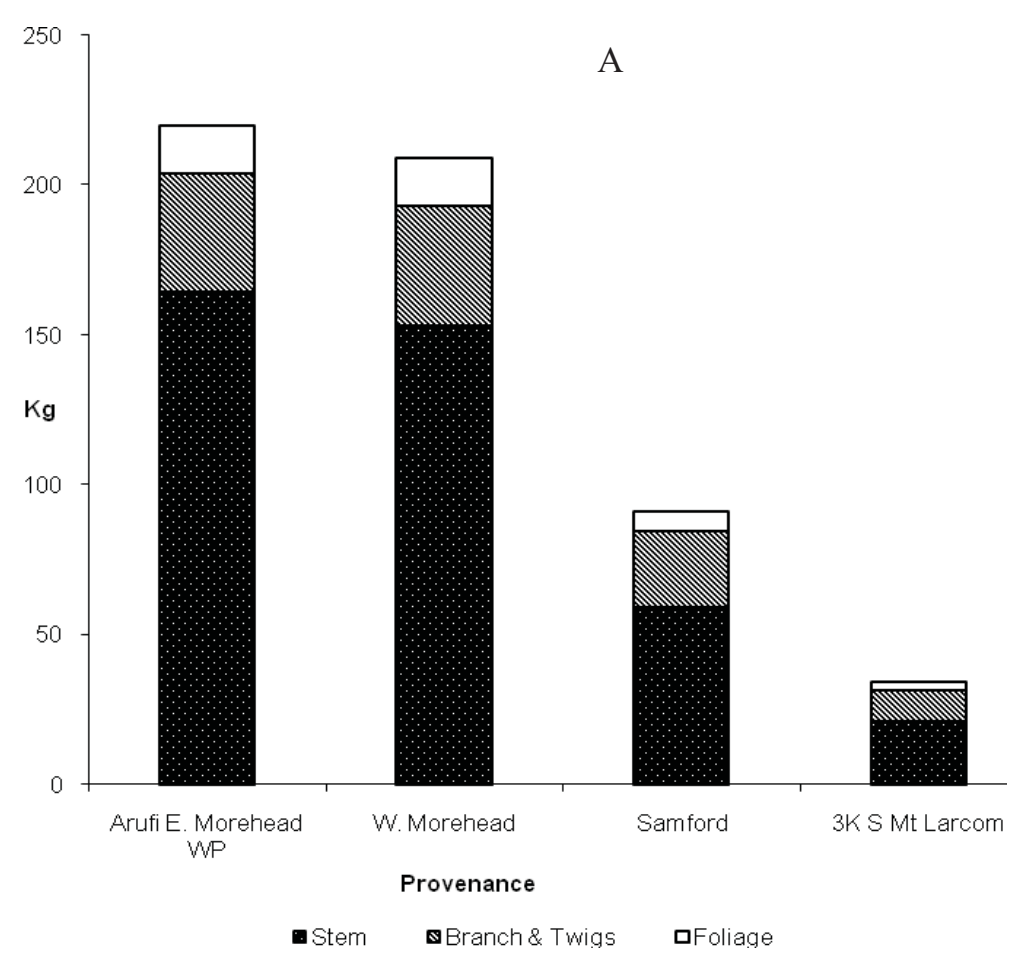

B

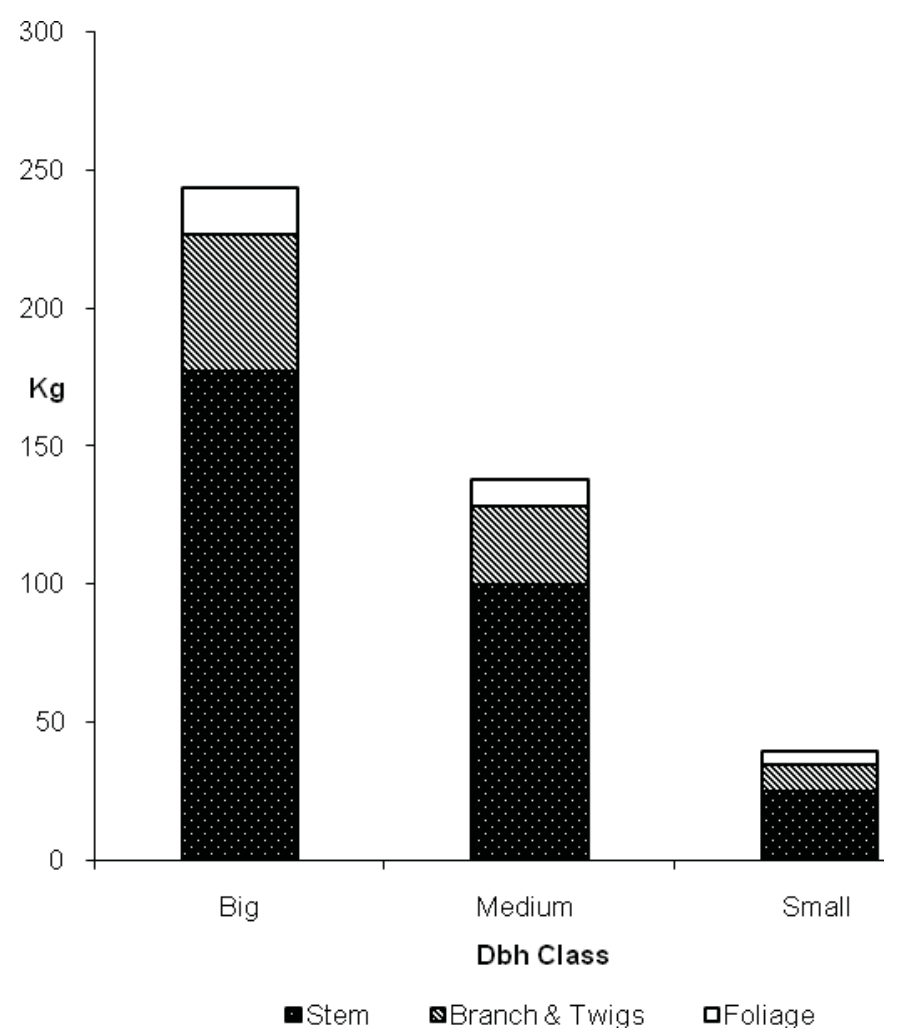

Figure 2. Total aboveground biomass of Acacia aulacocarpa with regards to provenances (A) and Dbh classes (B) 